\title{
EL PUPITRE DEL ESCRITOR
}

\author{
Silvia Hopenhayn
}

Las primeras ficciones de Mario Vargas Llosa — advierte S. Hopenhayn en este ensayo- se nutren de su experiencia en el Colegio Militar Leoncio Prado entre 1950 y 1951, como si el discurso de la autoridad lo hubiera impulsado a convertirse en autor. Libros como La ciudad y los perros (novela, 1963), Los jefes (cuentos, 1959), y Los cachorros (nouvelle, 1967) — plantea la autora - revelan el tironeo entre el impulso a gozar del adolescente (irrumpir de todas maneras) y la opresión del discurso institucionalizado. El campo y uso de la palabra (en su sanción semántica y tonalidad despótica)

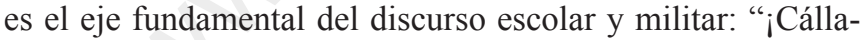
te!, cállate animal" frente a un tímido e impotente "Déjeme

Silvia Hopenhayn (1966) es escritora, crítica literaria y docente. Dicta cursos sobre personajes de la literatura desde hace varios años, a partir de su programa televisivo "Biografías fantásticas". Ha publicado los libros Cuentos reales y La espina infinitesimal (Emecé). En 2011 aparecerá su novela Elecciones primarias (Alfaguara). Escribe en el diario La Nación una columna semanal, "Libros en agenda". Ha hecho varios programas de televisión ("El fantasma", "La página en blanco", "La crítica", "La lengua suelta") y las biografías televisivas de distintos escritores, entre ellos de Carlos Fuentes, Adolfo Bioy Casares y Olga Orozco. Ha sido galardonada con el Premio Julio Cortázar, otorgado por la Cámara Argentina del Libro, y con el Konex de Oro por su labor literaria en los medios de comunicación. Silviahop@sion.com. 
hablar", es una escena clásica del cruce entre un cadete y el teniente Gamboa, en La ciudad y los perros.

El maltrato comienza, pues, por el maldecir. Basta una palabra ponzoñosa para que la herida empiece a supurar y produzca estragos. Tres ejemplos de la literatura se ligan a este vertiginoso arranque literario de Vargas Llosa: Stephen Dédalus en El retrato del artista adolescente, de James Joyce, Las tribulaciones del estudiante Törless, de Robert Musil y el personaje de Infancia, la novela de J. M. Coetzee. A través de un gesto restitutivo - señala S. Hopenhayn - el escritor peruano hizo del maltrato del decir, un decir de los malos tratos.

$\mathrm{L}$ as novelas de iniciación suelen nutrirse de una primera experiencia institucional, formadora y deformadora del sujeto y su destino: la escolaridad. La frase célebre y detractora de Bernard Shaw, "se terminó mi educación cuando empecé el colegio", puede cobrar matices en la misma literatura.

Escribir es una forma de salirse del marco obligado - vivido a la fuerza - al que se refiere el dramaturgo inglés; el escritor fuerza la letra hasta borronear su estamento, en busca de una corporeidad no corporativa. Pero tener un cuerpo es también entrar en un combate.

Las novelas del colegio, por llamarlas de algún modo, tienen un tufillo de revancha, de letra en la memoria, en busca del resarcimiento o, sencillamente, del alivio. Se trata de vaciar el tintero de la escritura impuesta y en ese desfiladero, hacerse de un nombre. De allí que prevalezca un cambio notable entre las novelas de iniciación y las siguientes, como si los escritores, luego de la inmersión en sus recuerdos de sumisión y aprendizaje, dejaran atrás la necesidad de enfrentarse con el aparato opresivo de la institución, construyendo en el proceso de escritura una nueva máquina de narrar.

\section{Del escarnio al sarcasmo}

Las novelas iniciáticas de Mario Vargas Llosa, en este sentido, son ejemplares. Tanto su nouvelle Los cachorros (1967) como La ciudad y los perros (1963) se incrustan en la muralla escolar a la que hace 
referencia Pink Floyd en su canción "The Wall", implorando, a un ritmo que parodia la marcha militar: "no más oscuros sarcasmos en el aula, profesor, deja a los niños solos."

Los niños están solos, al menos en el Leoncio Prado. Fueron dejados por sus padres, entregados al discurso de la autoridad. Por eso son novelas que desmantelan la trama de un engranaje, al mismo tiempo que lo ponen en marcha, a través de dos fuerzas contrapuestas: la opresión institucional y el impulso a gozar.

El resultado es el escarnio, palabra sustanciosa de etimología incierta. En el siglo XII, empezaba a sonar el término "escarnir" en todas las lenguas de la península ibérica, en su conexión con escarmiento. El origen germánico, skernjan, remite a burla, irrisión y se liga al término musical scherzo, de la misma familia genérica, más cercano a gracioso, divertido. Una suerte de preludio del sarcasmo. Al jugar con los prefijos, la palabra se desliza hacia la car-ne, dado que su práctica (la del escarnio) implica una herida y, el sarcasmo, una burla que hace doler.

Se trata, pues, de la herida en la carne a través del decir.

Esta praxis discursiva y vital, reflejada en las novelas, proviene en gran parte de la experiencia (encarnada) de Vargas Llosa, cuando él mismo estuvo internado en el Colegio Militar Leoncio Prado, entre 1950 y 1951. La vivencia o "aventura" (como le gusta llamarla) impulsó sus primeros escritos ${ }^{1}$.

Ahora bien, si la educación se termina cuando comienza el colegio... ¿qué comienza con el colegio?: El ladrido. O el ladrillo: another brick in the wall.

A través de estas primeras novelas, veremos, pues, la relación entre opresión y goce en el seno de las instituciones (familiar, escolar, militar) que culminan en la parodia de la milicia con Pantaleón y las visitadoras (1973).

La trama de La ciudad y los perros tiene forma de traición y denuncia. Comienza cuando el Cava, después de perder en una partida de cartas con un grupo de cadetes del Colegio Militar Leoncio Prado (CMLP), es obligado a robar el examen bimestral de química de quinto año, práctica bastante común entre los alumnos del internado. Consigue

${ }^{1}$ El cadete Vargas Llosa, de Sergio Vilela, 2011. Investigación exhaustiva sobre la experiencia del escritor peruano y sus compañeros en el Leoncio Prado. 
su cometido, pero un error desencadenará los hechos que se van sucediendo como torbellinos a lo largo de la novela: la detención indefinida de todos los cadetes hasta que el culpable aparezca; la desesperación del Esclavo ante lo que considera una injusticia (también en el plano amoroso) y la posterior delación de éste contra el culpable, la cual traerá como consecuencia la expulsión deshonrosa del Cava, así como la propia muerte del Esclavo en manos del Jaguar. El Jaguar, jefe del "Círculo", es el cadete que se erige como la expresión más sublime del orden instaurado, pues es cruel y autoritario. El Poeta lo acusa de haber asesinado al Esclavo en venganza por soplón. Sólo el teniente Gamboa da crédito a las palabras del Poeta, pero sus denuncias se estrellan contra la voluntad férrea de las autoridades del colegio que buscan evitar el escándalo de un crimen entre cadetes. Gamboa transita por el camino del desencanto y el cinismo tras descreer del ejército, institución a la cual se había entregado con devoción. Algo parecido, más en clave paródica, a la decepción que sufre Pantaleón, luego de su misión en Iquitos, en esa última conversación que sostiene con sus superiores:

-No sé cómo no acabó tuberculoso — aguanta la risa, ríe, se pone serio, vuelve a reír, tiene los ojos con lágrimas el Tigre Collazos- Todavía no descubro si es usted un pelotudo angelical o un cínico de la gran flauta.

Y agrega el general Victoria:

- Terminemos este asunto de una vez, ¿es cierto que se niega a pedir su baja?

- Me niego terminantemente, mi general- recobra la energía el capitán Panoja—. Toda mi vida está en el Ejército.

Semejante obstinación retuerce su destino. Lo designan intendente de la Guarnición de Pomata, en el sudeste del Perú. Y alegan sardónicamente:

En vez del río Amazonas tendrá el lago Titicaca [...]. En vez del calor de la selva, el frío de la puna [...]. Y en vez de las visitadoras, llamitas y vicuñas ${ }^{2}$.

La expulsión es una forma de destino. Por lo general, el expulsado es inerme al devenir. Así como a Pantoja lo sacan de Iquitos y lo

${ }^{2}$ Pantaleón y las visitadoras, pp. 326 y 328. 
mandan a Pomata, varios de los internados en el Leoncio Prado, quizá sin saberlo del todo, fueron corridos del seno familiar. ¿No se tratan de eso los internados? Los niños que viven en colegios suelen provenir de algún rechazo o imposición superyoica, como la del padre de Alberto que no tolera las bajas notas de su hijo.

-Esto se acabó. Es un escándalo. No voy a dejar que eches mi apellido por el suelo. Mañana comienzas tus clases con profesor particular para prepararte al ingreso.

— ¿Ingreso a dónde? — preguntó Alberto.

-Al Leoncio Prado. El internado te hará bien.

— ¿Interno? - Alberto lo miró asombrado.

-No me convence del todo ese colegio - dijo la madre-. Se puede enfermar. El clima de La Perla es muy húmedo.

- ¿No te importa que vaya a un colegio de cholos? - dijo Alberto.

-No, si es la única manera de que te compongas — dijo el padre- - . Con los curas puedes jugar, pero no con los militares. Además, en mi familia todos hemos sido siempre muy demócratas. Y, por último, el que es gente es gente en todas partes $^{3}$.

El caso de Ricardo Arana difiere de la sorpresa y el castigo. El Esclavo desea ingresar en el Leoncio Prado, lo anhela como un premio, tal es así que su padre, al comunicarle la noticia, le da diez soles "de propina" para que vaya al cine. La madre, al igual que la de Alberto, se muestra reticente.

- No estoy de acuerdo en que vaya interno a un colegio de militares.

Él levantó la vista.

— ¿Interno en un colegio de militares? — sus pupilas ardían-. Sería formidable, mamá, me gustaría mucho.

-Ah, las mujeres - dijo el padre, compasivamente-. Todas iguales. Estúpidas y sentimentales. Nunca comprenden nada. Anda, muchacho, explica a esta mujer que entrar al Colegio Militar es lo que más te conviene.

- Ni siquiera sabe lo que es — balbuceó la madre.

—Sí sé — replicó él, con fervor-. Es lo que más me conviene. Siempre te he dicho que quería ir interno. Mi papá tiene razón.

\footnotetext{
${ }^{3}$ La ciudad y los perros, p. 263.
} 
- Muchacho — dijo el padre - . Tu madre te cree un estúpido incapaz de razonar. ¿Comprendes ahora todo el mal que te ha hecho? ${ }^{4}$

La intolerancia entre los cónyuges produce estragos.

\section{Malos tratos}

Los personajes del primer libro de cuentos, Los jefes, llevan inseminado el ímpetu del púber, con toda su carga libidinal y desafiante. Precisamente en el cuento "Los jefes" se juega el doble enfrentamiento con el director del instituto y ante los propios compañeros. En este caso son los cadetes del Colegio San Miguel (fundado en 1835 en el norte del Perú), llamados "coyotes". A diferencia de "los perros", estos caninos salvajes aúllan, chillan o grañan y su contextura normal parece la de un animal desnutrido. "El fulgor de las pupilas, las vociferaciones, el escándalo indicaban que había llegado el momento de enfrentar al director." Esa furia del cadete modifica su semblante; se atasca en la mirada o cuelga de la boca. Uno imagina los rostros absortos de los adolescentes, al tiempo que sus ganas de despedazar al agresor, como el coyote al correcaminos, en el dibujo animado de Warner Brother, creado por la misma época en que suceden estos cuentos.

Los que realmente detentan el poder no refunfuñan; ellos hablan, gritan o vociferan. Son los que portan la palabra. Los dueños del decir. Ése es el verdadero lugar de la batalla: el campo y uso de la palabra. Eje fundamental del discurso despótico institucional:

“¡Cállate!, cállate animal” frente a un tímido e impotente, "Déjeme hablar", es una escena clásica del cruce entre un cadete y el teniente Gamboa, en La ciudad y los perros.

El maltrato comienza pues por el maldecir. Basta una palabra ponzoñosa para que la herida empiece a supurar y no deja de hacerlo hasta que esa misma palabra, pronunciada de igual manera en otra instancia de la vida, se erradique o resemantice.

Hay varios ejemplos proporcionados por la literatura con relación a la etapa escolar a la que hace referencia Vargas Llosa. El caso más canónico y próximo es el de Stephen Dédalus en El retrato del

${ }^{4}$ Ibídem, p. 246. 
artista adolescente, de James Joyce. Aquí el discurso institucional de la escuela no está teñido de militarismo sino — de manera bastante similar-de religiosidad.

¿Hay en esta sala algún chico que necesite ser azotado, Padre Arnall? — gritó el prefecto de estudios_- ¿Hay algún vago, algún gandul que necesite azotes? ¡A escribir! Tú, muchacho, ¿quién eres tú?

A Stephen se le saltó de golpe el corazón.

-Dédalus, señor.

— ¿Por qué no estás escribiendo como los demás?

No podía hablar del terror.

— ¿Por qué no está escribiendo éste, Padre Arnall?

- Se le han roto las gafas y le he exceptuado por eso de trabajar - contestó el Padre Arnall.

—¿Que se le han roto? ¿Qué es lo que oigo? ¿Cómo dices que es tu nombre? - dijo el prefecto de estudios.

-Dédalus, señor.

— ¡Sal aquí fuera, Dédalus! Holgazán y trapisondilla. Se te conoce el ardid en la cara. ¿Dónde se te rompieron las gafas? Dédalus salió a trompicones hasta el centro de la clase, ciego de miedo y de ansia.

— ¿Dónde se te rompieron las gafas? —repitió el prefecto.

-En la pista, señor.

— ¡Je je! ¡En la pista! —exclamó el prefecto de estudios- - Me sé de memoria esa artimaña.

Stephen levantó los ojos asombrado y vio por un momento la cara gris blancuzca y ya no joven del Padre Dolan, su cabeza calva y blanquecina con un poco de pelusilla a los lados, los cercos de acero de sus gafas y sus ojos sin color que le miraban a través de los cristales. ¿Por qué decía que se sabía de memoria aquella artimaña?

— ¡Haragán, maulero! — gritó el prefecto—. ¡Se me han roto las gafas! ¡Es una treta de estudiantes ya muy antigua ésa! ¡A ver, la mano, inmediatamente!

Stephen cerró los ojos y extendió su mano temblorosa, con la palma hacia arriba.

Sintió que el prefecto le tocaba un momento los dedos para ponerla plana y luego el silbido de las mangas de la sotana al levantarse la palmeta para dar. Un golpe ardiente, abrasador, punzante, como el chasquido de un bastón al quebrarse, obligó a la mano temblorosa a contraerse toda ella como una hoja en el fuego. Y al ruido, lágrimas ardientes de dolor se le 
agolparon en los ojos. Todo su cuerpo estaba estremecido de terror, el brazo le temblaba y la mano, agarrotada, ardiente, lívida, vacilaba como una hoja desgajada en el aire. Un grito que era una súplica de indulgencia le subió a los labios. Pero, aunque las lágrimas le escaldaban los ojos y las piernas le temblaban de miedo y de dolor, ahogó las lágrimas abrasadoras y el grito que le hervía en la garganta.

— ¡La otra mano! —exclamó el prefecto.

Stephen retiró el herido y tembloroso brazo derecho y extendió la mano izquierda. La manga de la sotana silbó otra vez al levantar la palmeta y un estallido punzante, ardiente, bárbaro, enloquecedor, obligó a la mano a contraerse, palma y dedos confundidos en una masa cárdena y palpitante. Las escaldantes lágrimas le brotaron de los ojos, y abrasado de vergüenza, de angustia y de terror, retiró el brazo y prorrumpió en un quejido. Su cuerpo se estremecía paralizado de espanto y, en medio de su confusión y de su rabia, sintió que el grito abrasador se le escapaba de la garganta y que las lágrimas ardientes le caían de los ojos y resbalaban por las arreboladas mejillas.

— ¡Arrodíllate! — gritó el prefecto.

Stephen se arrodilló prestamente, oprimiéndose las manos laceradas contra los costados. $\mathrm{Y}$ de pensar en aquellas manos, en un instante golpeadas y entumecidas de dolor, le dio pena de ellas mismas, como si no fueran las suyas propias, sino las de otra persona, de alguien por quien él sintiera lástima. Y al arrodillarse, calmando los últimos sollozos de su garganta y sintiendo el dolor punzante y ardiente oprimido contra los costados, pensó en aquellas manos que él había extendido con las palmas hacia arriba, y en la firme presión del prefecto al estirarle los dedos contraídos, y en aquellos dedos y aquellas palmas que, en una masa golpeada, entumecida, roja, temblaban, desvalidos, en el aire.

-A trabajar todo el mundo — gritó el prefecto de estudios desde la puerta- El Padre Dolan entrará todos los días para ver si hay algún chico perezoso y holgazán que necesite ser azotado. Todos los días. Todos los días.

La cita de Joyce se vincula con varias de las escenas descriptas por Vargas Llosa en La ciudad y los perros, aunque los golpes están más ligados al choque entre los propios cadetes. Ambas novelas se sitúan en un período de la vida, la adolescencia, en el que cambia el estado de la lengua. Se modula la violencia —el improperio, la injuria, la afrenta-, 
pero también se erige el mutismo. Este último se ve reflejado en Las tribulaciones del estudiante Törless, de Robert Musil, otra novela de iniciación clásica y renovadora, afín al despegue vargasllosiano. Aquí el maltrato es íntimo y callado. Publicada en 1906, narra la experiencia del estudiante Törless en un instituto militar del imperio austro-húngaro. Junto a sus compañeros Beinebert y Reiting, aprendices de sádicos, el protagonista advierte que sexualidad y moral fundamentan la violación (antes de que Foucault estableciera fundamentos historiográficos al respecto).

Como testigo no participante, el joven Törless presencia el abuso del efebo Basini en la buhardilla del colegio para bajarle los pantalones, obligándolo a dejarse penetrar. Lo más interesante es que el mismo Basini será quien regrese al lugar señalado cada vez que sus compañeros lo acosen; como una presa que, cabizbaja, retorna a la trampa anticipando el recorrido del perseguidor.

En La ciudad y los perros, el acoso es distinto, pero le rinde homenaje a esta escena llevada al cine en 1966 por Volker Schloendorff. Aquí el dictamen es más ambiguo. No siempre el violento es malo. Hasta la violencia tiene sus virtudes. En el Leoncio Prado se resaltan los valores de sumisión, pero también de lealtad. El Jaguar, por ejemplo, ocupa un lugar de rebeldía y, a su vez, de sanción. Es el único cadete de tercero que se niega a ser llamado Perro, luego del ritual de iniciación.

Veamos de qué se trata este nombramiento. La narración se remonta a tiempo atrás, cuando Alberto Fernández y sus compañeros recién ingresan al colegio para cursar el tercer año de secundaria, y reciben el bautismo por parte de los alumnos de cuarto, del que también participan los de quinto. Llamarlos perros implica escenificar la palabra, poner en juego sus connotaciones. El apelativo requiere de una secuencia de actos denigratorios. Como a los que se somete Ricardo Arana -ya antes apodado el Esclavo - a quien le hacen cantar cien veces "soy un perro" con distintos ritmos: corrido mexicano, bolero, música de mambo y vals criollo.

La crudeza de la experiencia escolar más sórdida no es rígida en su narración. Vargas Llosa consigue que hasta el mismo vejamen conlleve un atisbo de torpeza adolescente inmanejable que aligera la prosa. Lo impulsivo deviene frase torrente.

Por otra parte, el autor le otorga al relato un rango de memoria infiel: ¿qué se recuerda de la experiencia institucional? ¿La opresión 
que viene de afuera como una guadaña devastadora o la propia reacción, ya sea de inermidad o repliegue, incluso de réplica? ¿Qué es más relevante, o hace mella en la memoria entonces, el discurso del otro o la respuesta que aparece en uno?

En este sentido, también puede separarse de la experiencia el material de estudio - frecuentemente olvidado - del efecto del maestro - muchas veces incrustado. Freud, en su nota introductora a Zur Psychologie des Gymnasiasten, cuenta una historia personal que ilustra la verdadera curiosidad del alumno o del cadete. Al encontrarse, ya adulto, con un viejo maestro que le evoca su pasado en una institución escolar, reflexiona: "No sé que nos reclamaba con más intensidad ni qué era más sustantivo para nosotros: ocuparnos de las ciencias que nos enseñaban o de la personalidad de nuestros maestros. Provocaron nuestras más intensas revueltas y nos compelieron a la más total sumisión".

La marca de la experiencia aparece en la ficción. El cuento que se hace de lo vivido. Podría pensarse incluso que la propia vida se establece por escrito. La verdad del relato - por llamarla de alguna manera, y evitando apelar al bien visto "verosímil" - proviene del despliegue imaginario de lo que no llegó a ser de esa amenaza latente. Como decía Lacan: "La verdad tiene estructura de ficción."

En Vargas Llosa, el empuje semántico a representar el dolor en su constitución más íntima, convierte a la lengua en un azote sincero. La subjetividad se combina con el lugar de pertenencia. En la lengua se cuelan tonos. Los del alma y de los de distintos barrios, en alternancia con un lunfardo muy localista: "Era chanconcito (pero no sabón") 5 .

El lenguaje se vivifica mediante la audacia de la mixtura; difícilmente a un austríaco como Musil se le hubiera ocurrido contarlo como lo hace Vargas Llosa, desde ninguno de los aspectos narrativos a los que el peruano se anima: la puntuación, como un salpicado, la procacidad en la pregunta, la fusión de la trama con el estilo: allí donde pululan gallinas, la prosa aparece picoteada. Es el momento en que los cadetes descubren que detrás del galpón de los soldados hay gallinas y planean satisfacerse con ellas. Las aves se rebelan, los picotean (“¿y qué me dicen si capa a alguien a punto de aletazos, qué me dicen?", argumenta uno de ellos). Al ponerse difícil la situación, surge la propuesta de ofrecer a los más débiles. Los gordos fofos y los flacos lánguidos. Blanco fácil de incipientes perversos.

\footnotetext{
${ }^{5}$ Los cachorros, p. 179.
} 
¿Y qué tal si nos tiramos al gordito?, dijo el Rulos [...] ¿Tú no lo has pellizcado nunca?

El episodio es tenso e hilarante. Boa, Cava, Rulos, el Jaguar, tratando de atrapar a las gallinas ("Aquí hay un hilo para el pico, no la sueltes que a lo mejor se vuela.", "oye, ¿y si me infecto?”). En ese momento, el Jaguar azuza a todos con una pregunta instigadora: “¿Quién dijo miedo, alguien dijo miedo?"6.

El miedo a decir lo que se piensa, a hacer lo que se ansía. Miedo a lo femenino, a fin de cuentas. A las gallinas, a las chicas representadas por gallinas. $\mathrm{Y}$ a ser ellos mismos unos gallinas.

Pero así como con las aves de granja el estilo se entrecorta, frente a las "chicas", sobre todo si son del barrio de Miraflores, las frases se estiran hasta pillarles la cintura. Es la retórica del regodeo y la argucia.

\section{Letra que ladra}

El miedo es motor de la violencia. Porque se lo calla. Es el miedo a tener miedo y, sobre todo, a decirlo. El Jaguar lo confirma con su pregunta: "¿quién dijo miedo?”.

El varoncito de Infancia, la novela evocativa de J. M. Coetzee (Premio Nobel, al igual que Vargas Llosa, pero en 2003), también se enfrenta con el acoso, pero, en este caso, del pensamiento. Cuando le hacen preguntas para averiguar su identidad religiosa y política, apura sus respuestas con el fin de no ser descubierto en sus aficiones verdaderas. En el año 1947, no puede decir en el colegio que está a favor de los rusos; mientras que en su casa colecciona afiches de Lenin y tiene maquetas de tanques rusos de la primera guerra mundial, le gustan los colores de la bandera rusa y prefiere toda la vida un paisaje nevado que la estepa africana.

Aprende a esconder su elección. La mejor manera que encuentra para hacerlo es asumiendo cualquier otra identidad que se le aparezca oportuna y satisfaga a las personas que lo califican. Ser lo que los otros esperan que sea, mientras guarda y practica en secreto quien realmente desea ser. Así, cuando el maestro le pregunta por su religión, ante la opción protestante, católico o judío, contesta falsamente: "católico".

\footnotetext{
${ }^{6}$ La ciudad y los perros, p. 46.
} 
Su respuesta implica la construcción de un semblante. Improvisa métodos de aprendizaje veloz o de simulo: mueve los labios sin rezar, dejándose llevar por la aliteración de las vocales para que su boca resulte creíble. Y cuando los compañeros lo indagan — si ha ido a catequesis o si tomó la comunión o si se ha confesado-, él responde a todo que sí, que lo hizo en Ciudad del Cabo; total nadie lo va a verificar. Son las ventajas de un niño en desarraigo: es fácil creer en su historia inventada en otra parte. Como si su biografía estuviera resguardada en la lejanía de lo acontecido.

En Vargas Llosa, el maltrato agudiza la lengua. La violencia del vituperio se combina con el argot, como dijimos antes, adquiriendo una dimensión de neologismo vivaz. Lo que no se entiende, se lo escucha. El sentido se forma en la musicalidad de la lengua.

El mismo ladrido del perro forma parte de un estilo de interacción. Esto sucede cuando varios provocan a Ricardo Arana, en La ciudad y los perros, y ni siquiera se presenta un rostro. Sólo es una voz que lo increpa.

— ¿Usted es un perro o un ser humano? — preguntó la voz.

-Un perro, mi cadete.

-Entonces, ¿qué hace de pie? Los perros andan a cuatro patas.

- Bueno - dijo la voz-. Cuando dos perros se encuentran en la calle, ¿qué hacen? Responda, cadete. A usted le hablo.

El Esclavo recibió un puntapié en el trasero y al instante contestó:

-No sé, mi cadete.

—Pelean — dijo la voz-. Ladran y se lanzan uno encima del otro. Y se muerden.

El Esclavo no recuerda la cara del muchacho que fue bautizado con él. Debía ser de una de las últimas secciones, porque era pequeño. Estaba con el rostro desfigurado por el miedo y, apenas calló la voz, se vino contra él, ladrando y echando espuma por la boca, y de pronto, el Esclavo sintió en el hombro un mordisco de perro rabioso y entonces todo su cuerpo reaccionó, y mientras ladraba y mordía, tenía la certeza de que su piel se había cubierto de una pelambre dura, que su boca era un hocico puntiagudo y que, sobre su lomo, su cola chasqueaba como un látigo ${ }^{7}$.

${ }^{7}$ Ibídem, pp. 64-65. 
Voz y ladrido. Dimensión sicótica de la comunicación. Ni palabra ni letra. Nada se dice ni se inscribe. Es el sonido de la acción. Hacerle algo al otro, ya no con las palabras como señalaba Austin, con respecto a los enunciados performativos, sino con la voz. La violencia de la voz genera una suerte de adicción auditiva, y su consecuente obediencia. De allí que el cadete menor se lanza sobre el Esclavo por pura rabia, una rabia que le viene del oído ${ }^{8}$.

\section{Brutos y lívidos}

La segregación aparece en los textos de Vargas Llosa como una fatalidad. De dónde se sale o a dónde se llega. El primer lugar es el más íntimo: la familia. El padre segrega y de distintas maneras. Con la voz, como decíamos antes, pero también con la mirada. Esa mirada que se retira siempre antes de que alcance a decir algo, a expresar un sentimiento acogedor: el mismo padre que insiste en enviar a Alberto al Leoncio Prado, arguyendo que el internado es la mejor formación, mientras que su madre manifiesta un desacuerdo con tanto recaudo que jamás incide en la toma de decisiones. El padre, en cambio, lo descalifica, aislándolo en un internado.

Ya en "Los jefes", la segregación se manifiesta entre "los coyotes". "Quiere fregarnos, el serrano". Se nombra a las personas por su lugar de procedencia, con un tinte denigratorio. Por apodos y apartados. El racismo en la sociedad peruana es muy complejo. Recordemos que la alcurnia viene del Alto Perú; incluso desde la lengua, es quizá el castellano más rico, prolífico y diverso. Pero también es un país que albergó rápidamente la pobreza y actualmente la población padece de una desigualdad que se produjo, como la erosión del mar, a lo largo de la historia.

El color de la piel es uno de los rasgos más difamatorios. Por decirlo malamente, en términos darwinianos, se asemeja a un signo evolutivo. Cuanto más oscura la piel, menos próximo al colono europeo.

Por otra parte no es lo mismo ser de Miraflores que de otro barrio, de la ciudad que de un pueblo, costeros, citadinos o serranos. En La ciudad y los perros la división es tajante, en cuanto a la estirpe militar: "Casi todos los militares son serranos. No creo que a un costeño se le ocurra ser militar".

${ }^{8}$ Del subjuntivo al imperativo: "Qué se diga queda olvidado detrás de lo que se dice en lo que se escucha" (Lacan, Seminario 19). 
La procedencia en todo caso es inevitable. Más humillante es la injuria al ser. Los problemas entre las personas surgen cuando se ataca el ser del otro, se lo cuestiona o vilipendia: cuando se apunta a lo singular. Es lo que ocurre cuando Cuéllar, el protagonista de Los cachorros, ingresa en el colegio Champagnat ${ }^{9}$.

Precisamente, el bautismo de Cuéllar atenta al ser, lo ridiculiza. "Pichulita", lo llama Gumucio, un compañerito de clase. Él se resiste, llora, empeorando la situación, reforzando su apodo, dándole cabida y forma.

Por ese tiempo [...] comenzaron a decirle Pichulita. [A]1 principio Cuéllar, hermano, lloraba, me están diciendo una mala palabra, como un marica, ¿quién?, ¿qué te dicen?, una cosa fea, Hermano, le daba vergüenza repetírsela, tartamudeando y las lágrimas que se le saltaban, y después en los recreos los alumnos de otros años, Pichulita qué hubo [...]. [S]e enfurecía, qué has dicho, Pichulita he dicho, blanco de cólera, maricón, temblándole las manos y la voz, a ver repite si te atreves, Pichulita, ya me atreví y qué pasaba y él entonces cerraba los ojos y, tal como le había aconsejado su papá, no te dejes muchacho, se lanzaba, rómpeles la jeta, y los desafiaba, le pisas el pie y bandangán, y se trompeaba, un sopapo [...] lo mandas al suelo y se acabó, en la clase, en la capilla, no te fregarán más ${ }^{10}$.

La dignidad humana suele definirse a través de las palabras; en este caso el padre de Cuéllar apunta a derribar con las propias manos el discurso despreciativo y manipulador. Tal vez sea una forma de plantear una desarticulación.

\section{Revancha, restitución}

La ficción puede ser una buena lección para la realidad, o su repentina contracara. Así parece haber ocurrido con la obra primeriza de

${ }^{9}$ Hay que tener en cuenta, así como antes mencionamos el San Miguel, que los colegios, sobre todo limeños, tienen una tradición fuerte, en este caso se trata de uno de los más prestigiosos de la ciudad, institución de los Hermanos Maristas, situado en Miraflores, donde asisten los hijos de la alta burguesía; el colegio fue creado por Marcelino José Benito Champagnat Chirat (1789-1840), sacerdote fundador de varias escuelas en toda la región.

${ }^{10}$ Los cachorros, p. 194. 
Vargas Llosa para que el 11 de marzo del 2011, el mismísimo Colegio Militar Leoncio Prado, donde pasó el escritor tercero y cuarto año, entre 1950 y 1951, lo convocara para rendirle homenaje. Se hizo humo la leyenda de la quema en el patio del colegio de varios ejemplares de $L a$ ciudad y los perros en el momento de su publicación, por parte de los militares.

Esta vez, el coronel David Ojeda Parra, actual director del CMLP, y el general de División Juan Urcariegui Reyes, comandante general de la Región Militar de Centro, festejaron su obra y sus honores, en un acto emotivo compartido por los demás cadetes que pertenecieron a la séptima promoción.

Vargas Llosa ha logrado que el destino se muerda la cola, convirtiendo los efectos del discurso autoritario institucional en causa de su literatura.

\section{REFERENCIAS}

Coetzee, J. M. Infancia. Mondadori, 2010.

Freud, Sigmund. Sobre la psicología del colegial. Obras completas, Tomo III. Biblioteca Nueva, 1995.

Joyce, James. Retrato del artista adolescente. RBA, 1995.

Musil, Robert. Las tribulaciones del estudiante Törless. Seix Barral, 2002.

Vilela, Sergio. El cadete Vargas Llosa. Alcalá Grupo Editorial, 2011.

Vargas Llosa, Mario. Pantaleón y las visitadoras [1973]. Ed. Alfaguara, 1997.

L La ciudad y los perros [1962]. Ed. Alfaguara, 1997.

- Los cachorros [1967]. Ed. Austral, de Espasa, 2010.

Lacan, Jacques. Seminario 19, 1971/72 (inédito). 